\title{
Natural Rubber Based Composites Comprising Different Types of Carbon-Silica Hybrid Fillers. Comparative Study on Their Electric, Dielectric and Microwave Properties, and Possible Applications
}

\author{
Ahmed A. Al-Ghamdi', Omar A. Al-Hartomy1, Falleh R. Al-Solamy², Nikolay Dishovsky³, \\ Mihail Mihaylov3, Petrunka Malinova ${ }^{3}$, Nikolay Atanasov ${ }^{4,5}$ \\ ${ }^{1}$ Department of Physics, Faculty of Science, King Abdulaziz University, Jeddah, KSA \\ ${ }^{2}$ Department of Mathematics, Faculty of Science, King Abdulaziz University, Jeddah, KSA \\ ${ }^{3}$ Department of Polymer Engineering, University of Chemical Technology and Metallurgy, Sofia, Bulgaria \\ ${ }^{4}$ Department of Telecommunications, University of Telecommunications and Post, Sofia, Bulgaria \\ ${ }^{5}$ Department of Communication and Computer Engineering, South-West University "Neofit Rilski" \\ of Blagoevgrad, Blagoevgrad, Bulgaria \\ Email: dishov@uctm.edu
}

Received 5 May 2016; accepted 10 June 2016; published 13 June 2016

Copyright (C) 2016 by authors and Scientific Research Publishing Inc.

This work is licensed under the Creative Commons Attribution International License (CC BY).

http://creativecommons.org/licenses/by/4.0/

c) (i) Open Access

\section{Abstract}

The paper presents a comparative study on the electric, dielectric and microwave properties of natural rubber based composites comprising dual phase fillers prepared from furnace carbon black or conductive carbon black with a different amount of silica. It has been established that, the specifics of the carbon phase have a marked strong effect upon the properties mentioned above. The interpenetration of the two filler phases and the grade of isolation of the conductive carbon phase by the dielectric one depend on the ratio between them. On the other hand, that leads to a change in all properties of the studied composites, which allows tailoring those characteristics.

\section{Keywords}

Polymer Composites, Hybrid Fillers, Dielectric Properties, Microwave Properties

How to cite this paper: Al-Ghamdi, A.A., Al-Hartomy, O.A., Al-Solamy, F.R., Dishovsky, N., Mihaylov, M., Malinova, P. and Atanasov, N. (2016) Natural Rubber Based Composites Comprising Different Types of Carbon-Silica Hybrid Fillers. Comparative Study on Their Electric, Dielectric and Microwave Properties, and Possible Applications. Materials Sciences and Applications, 7, 295-306. http://dx.doi.org/10.4236/msa.2016.76027 


\section{Introduction}

In the recent decades the technological progress has been causing a new type of contamination, namely, electromagnetic interference (EMI). EMI is an electromagnetic signal emitted by an electronic source which disturbs the performance of other similar devices in its vicinity [1]-[4]. Therefore, microwave absorbing materials have been finding wider application in modern technologies such as electronics and telecommunications [5]. The usage of such absorbers aims at reducing the radiation reflection, and ensuring EMI shielding and protection [5][9]. Being elastic, easy to process, possessing good mechanical properties and highly resistant to various natural factors, elastomers have been finding wider application in the design of microwave absorbing materials. However, most of the neat elastomers are dielectrics and absolutely transparent to electromagnetic radiation. For that reason, the elastomer based microwave absorbing materials consist of a rubber matrix and electromagnetic wave absorbents. The necessary electromagnetic performances of a rubber absorbing material (RAM) are owing to the electromagnetic wave absorbents while the rubber is their carrier [10] [11].

An essential requirement for a good microwave absorbing material is the so-called "impedance matching", which can decrease the reflection of the incident wave on the interface between free spaces and absorbing materials and be in favour of the improvement of absorbing properties. Dielectric and magnetic losses are also important parameters determining the absorbing properties of microwave absorbents [12]. As known, the main principles for developing elastomer based microwave absorbers are: finding a suitable dielectric rubber matrix and filler or a system of fillers possessing high dielectric and/or magnetic loss values (such as conductive carbon black, $\gamma-\mathrm{Fe}_{2} \mathrm{O}_{3}, \mathrm{Ni}-\mathrm{Zn}-\mathrm{Fe}_{2} \mathrm{O}_{4}, \mathrm{Fe}_{3} \mathrm{O}_{4}, \mathrm{SrFe}_{12} \mathrm{O}_{19}$, etc.) [13]-[18]. The crucial factor to obtain good microwave absorbers is the ability of the dielectric matrix or of any other dielectric phase to isolate completely the particles of the conducting filler, i.e. its particles to get in fewer contacts with each other [19].

On the other hand, the constant improvement in wireless technologies and communications in recent years has set the necessity of creating antennae of miniature size, simplified structure and wider broadband. The compounds being used currently are copper coated laminates with high dielectric constant, which in fact are ceramic-polymer composites [20]. The shortcomings of the high dielectric ceramics are their being of high density and friability as well as hard process. Those shortcomings are overcome using various polymers [21] [22]. In this connection, Jin and co-workers have studied the properties of PTFE based composites, comprising $\mathrm{SrTiO}_{3}$ of different amounts. The authors have established that, composites comprising about 60 wt $\%$ of $\mathrm{SrTiO}_{3}$, whose dielectric constant is $12\left(\varepsilon_{r}^{\prime}=12\right)$, are suitable for microwave radio frequency antenna applications [22]. In wideband communication systems, the antenna is the sole interfacing device attached to both the transmitter and receiver. It has been found that, the impedance bandwidth is of crucial importance for a high performance communication system. The operative frequency of an antenna is affected by dielectric permittivity which is influenced by the types of materials that it is made of. Antennas require a dielectric constant that is high enough (reflection loss lower than $-10 \mathrm{~dB}$ in wide frequency range) for sufficient coupling to the excitation source in order to operate efficiently [23].

Currently dual-phase furnace carbon black/silica fillers find wider application in rubber industry [24] [25]. According to our working hypothesis, if the silica phase (dielectric phase) in the hybrid fillers is located over the surface or penetrates the inner domains of carbon black aggregates (conductive phase), it should isolate them and restrict their interaction. Thus, the electric (conductivity), dielectric (dielectric constant) and microwave (impedance matching, reflection, absorption, etc.) properties of the composites comprising hybrid fillers could be controlled by varying the ratio between their conductive and dielectric phases. We have chosen to use impregnation technology for the preparation of such fillers since it is an affordable method facilitating an easy control over the quantitative ratio between the dielectric and conductive phases in the hybrid fillers.

The paper aims at comparing the electric, dielectric and microwave properties of natural rubber based composites comprising dual phase fillers prepared from furnace carbon black and conductive carbon black with a different amount of silicon dioxide (silica) and at evaluating the effect that the specifics of carbon phase have upon the composites properties. Another aim is to assess the possibilities for their application as microwave absorbers, shielding materials as well as for microwave radio frequency antennae.

\section{Experimental}

\subsection{Materials}

Natural rubber SVR 10 supplied by Hong Thanh Rubber Pty. Ltd. was used as a polymer matrix. The other in- 
gredients such as zinc oxide (ZnO), stearic acid, N-tert-butyl-2-benzothiazole sulfenamide (TBBS) and sulphur (S) were commercial grades and used without further purification.

\subsection{Hybrid Fillers Preparation}

The hybrid fillers studied were prepared by modification with silicasol ( $40 \%$ of silica, $\mathrm{pH}-9$ and density of 1.3 $\mathrm{g} / \mathrm{cm}^{3}$ ) of either industrial furnace carbon black type N 330 with specific surface area (BET) $75 \mathrm{~m}^{2} / \mathrm{g}$ or conductive Printex XE-2B carbon black with specific surface area (BET) $1000 \mathrm{~m}^{2} / \mathrm{g}$ (both produced by Orion Engineered Carbons $\mathrm{GmbH}$ ). A mixture of $100 \mathrm{~g}$ of N 330 or Printex XE-2B carbon black and the needed amount of silicasol, corresponding to $3 \%$ or $7 \%$ of silica, was placed into a ball mill and $1.6 \mathrm{~L}$ of distilled water was poured over it. The mixture was impregnated for 2 hours. The product was placed into a drying chamber at $150^{\circ} \mathrm{C}$ and stayed till its complete drying. After that it was ground again in a ball mill for 2 hours. Then it was thermally treated at $440^{\circ} \mathrm{C}$ under $10^{-2} \mathrm{~mm} \mathrm{Hg}$ vacuum for 2 hours in a reactor designed especially for the purpose. Thus, the thermal activation could be run at higher temperature without a negative effect upon the carbon black. Being removed from the reactor the product was ground again in a ball mill and was ready for further investigations. Four hybrid fillers based on furnace carbon black N 330 and Printex XE-2B conductive black, and 3\% or 7\% of silica were prepared according to the above method. The fillers were denoted as N 330/3, N 330/7, $\mathrm{Pr} / \mathrm{Si} 3$ and $\mathrm{Pr} / \mathrm{Si}$ 7, respectively.

\subsection{Preparation of Rubber Composites}

The rubber compounds studied were prepared on a two-roll laboratory mill (rolls length/diameter $320 \times 160$ $\mathrm{mm}$ ). Table 1 presents the compositions of the rubber compounds studied. The vulcanization of the natural rubber based compounds was carried out on an electrically heated hydraulic press using a special homemade mold at $150^{\circ} \mathrm{C}$ and $10 \mathrm{MPa}$.

\subsection{Measurements}

\subsubsection{Electrical Properties Measurement}

\section{1) Volume Resistivity}

Volume resistivity $\left(\rho_{v}, \Omega \cdot \mathrm{m}\right)$ of the studied composites was measured using two electrodes (2-terminal method) and calculated by the Equation (1):

$$
\rho_{v}=R_{v} \frac{S}{h}
$$

Table 1. Compositions of the investigated natural rubber based composites (phr).

\begin{tabular}{|c|c|c|c|c|c|c|}
\hline & NR 1 & NR 2 & NR 3 & NR 4 & NR 5 & NR 6 \\
\hline Natural Rubber-SVR 10 & 100.0 & 100.0 & 100.0 & 100.0 & 100.0 & 100.0 \\
\hline Zinc Oxide & 3.0 & 3.0 & 3.0 & 3.0 & 3.0 & 3.0 \\
\hline Stearic Acid & 2.0 & 2.0 & 2.0 & 2.0 & 2.0 & 2.0 \\
\hline Carbon Black N 330 & 70.0 & - & - & - & - & - \\
\hline N 330/3 & - & 70.0 & - & - & - & - \\
\hline N 330/7 & - & - & 70.0 & - & - & - \\
\hline Printex XE-2B & - & - & - & 70.0 & - & - \\
\hline Pr/Si 3 & - & - & - & - & 70.0 & - \\
\hline $\operatorname{Pr} / \mathrm{Si} 7$ & - & - & - & - & - & 70.0 \\
\hline TBBS & 1.5 & 1.5 & 1.5 & 1.5 & 1.5 & 1.5 \\
\hline Sulfur & 2.0 & 2.0 & 2.0 & 2.0 & 2.0 & 2.0 \\
\hline
\end{tabular}


where:

$R_{v}$ —ohmic resistance between the electrodes; $h$ —sample thickness between the electrodes, m; $S$ —cross sectional area of the measuring electrode, $\mathrm{m}^{2}$.

A Wheatstone bridge was used to measure the resistance.

\section{2) Surface Resistivity}

The surface resistivity of the samples was calculated using Equation (2):

$$
\rho_{\mathrm{s}}=100 R_{\mathrm{s}}
$$

where $R_{S}$ is the resistivity measured in $\Omega$.

\subsubsection{Dielectric Properties Measurement}

The dielectric properties of the composite materials were measured by the resonant perturbation method. According to the resonant perturbation method, the tested sample is introduced into a resonator, and the electromagnetic parameters of the sample are deduced from the change in the resonant frequency and quality factor of the resonator [26]. For the rectangular cavity, $\mathrm{TE}_{10 \mathrm{n}}$ modes are used for the complex permittivity measurements. The sample was placed on the spot of maximum intensity of electric field, where $\mathrm{n}$ = odd is always adopted, because the sample's position can be located easily as the geometric centre of the cavity is one of the maximum positions [27]. The formulas for the real and imaginary parts of the relative permittivity are as follows [28]:

$$
\begin{aligned}
& \varepsilon^{\prime}=\left(\frac{f_{c}-f_{s}}{2 f_{s}}\right) \cdot\left(\frac{V_{c}}{V_{s}}\right)+1 \\
& \varepsilon^{\prime \prime}=\left(\frac{V_{c}}{4 V_{s}}\right) \cdot\left(\frac{1}{Q_{s}}-\frac{1}{Q_{c}}\right)
\end{aligned}
$$

where $f_{c}$ and $Q_{c}$ are resonance frequency and $Q$-factor of the cavity without an inserted sample, $f_{s}$ and $Q_{s}$, are with an inserted sample, respectively; $V_{c}$ is the volume of the cavity; $V_{s}$ is the volume of the sample.

\subsubsection{Microwave Properties Measurement}

The total shielding effectiveness was defined as the ratio between the incident power on the sample $P_{I}$ and the transmitted power $P_{T}$ in accordance with Equation (5) [29]-[31]:

$$
S E_{T}=10 \log \frac{P_{I}}{P_{T}}
$$

The total shielding effectiveness $\left(S E_{T}\right.$, in $\left.\mathrm{dB}\right)$ and the reflective shielding effectiveness of the sample surface $\left(S E_{R}\right.$, in $\left.\mathrm{dB}\right)$ were determined by Equations (6) and (7) [32]-[35]:

$$
S E_{T}=-10 \lg T \text {, }
$$

where $T=\left|P_{T} / P_{I}\right|=\left|S_{21}\right|^{2}$.

$$
S E_{R}=-10 \lg (1-R)
$$

where $R=\left|P_{R} / P_{I}\right|=\left|S_{11}\right|^{2}$.

$S_{11}$ and $S_{21}$ are the complex scattering parameters or $S$-parameters ( $S_{11}$ corresponds to the reflection coefficient and $S_{21}$-to the transmission coefficient).

The absorptive shielding effectiveness $\left(S E_{A}\right)$ was calculated as the difference between (6) and (7), as shown in Equation (8):

$$
S E_{A}=S E_{T}-S E_{R}
$$

The attenuation coefficient $(\alpha, \mathrm{dB} / \mathrm{cm})$ was determined using Equation (8). Substituting $S E_{T}$ and $S E_{R}$ in it with Equations (6) and (7), Equation (9) is obtained.

$$
S E_{A}=10 \lg \left(\frac{P_{I}\left(1-\left|S_{11}\right|^{2}\right)}{P_{T}}\right)
$$


For determining the attenuation coefficient, Equation (9) was divided by the thickness of the sample $d$ in centimetres, as shown in Equation (10).

$$
\alpha=\frac{S E_{A}}{d}=10 \lg \left(\frac{P_{T}}{P_{I}\left(1-\left|S_{11}\right|^{2}\right)}\right)
$$

The reflection losses were determined according to Equation (11).

$$
R_{L}=20 \log _{10}|\Gamma|
$$

where $R_{L}$ is the reflection loss, $|\Gamma|$ is the reflection coefficient.

The measurements were carried out at room temperature varying from $19^{\circ} \mathrm{C}$ up to $24^{\circ} \mathrm{C}$ and incident power $P_{I}$ at the inlet of the coaxial measuring line varying from $800 \mu \mathrm{W}$ up to $1300 \mu \mathrm{W}$ within the frequency range of 1 $\mathrm{GHz}$ to $12 \mathrm{GHz}$.

\section{Results and Discussion}

\subsection{Electrical Properties}

Most elastomers are dielectrics, i.e. they have low conductivity (less than $10^{-11} \mathrm{~S} / \mathrm{m}$ ). The introduction of various conductive nanofillers might improve considerably their conductivity due to the percolation pathways in the elastomer matrix built by the conductive filler. Thus the electroconductivity increases drastically at a certain filler concentration termed as "percolation threshold". That widens to a great extent the application areas of elastomer composites [36]-[39].

Figure 1 presents the filler concentration dependence of volume resistivity and surface resistivity. Our previous studies have shown $7.5 \mathrm{phr}$ to be the critical concentration of Printex XE-2B in the rubber matrix at which the percolation threshold is reached [40]. However, in the case aiming at determining the effect that the second-dielectric phase (silica) in the studied hybrid fillers has, the filler concentration in the studied composites is much higher than the one needed to pass the percolation threshold. As Figure 1 shows, $\rho_{v}$ and $\rho_{s}$ values for the composites comprising carbon black N 330 (NR 1) and for those comprising hybrid fillers on its base (NR 2 and NR 3) vary in the range $2.2 \times 10^{3}$ to $3.8 \times 10^{3} \Omega \cdot \mathrm{m}$ and $2.3 \times 10^{6}-6.0 \times 10^{6} \Omega$, respectively. The composites comprising conductive carbon black Printex XE-2B (NR 4) and those comprising hybrid fillers on its base (NR 5 and NR 6) have much lower $\rho_{v}$ and $\rho_{s}$ values-3.6 to $4.9 \Omega \cdot \mathrm{m}$ and $5.2 \times 10^{2}-6.3 \times 10^{2} \Omega$, respectively, i.e. those composites have higher conductivity and can be classified as true conductors. The well pronounced difference in $\rho_{v}$ and $\rho_{s}$ values for the composites is due to the difference in the size of carbon black particles, to the difference in the their specific surface area, respectively. The specific surface area (BET) of furnace carbon black N 330 is

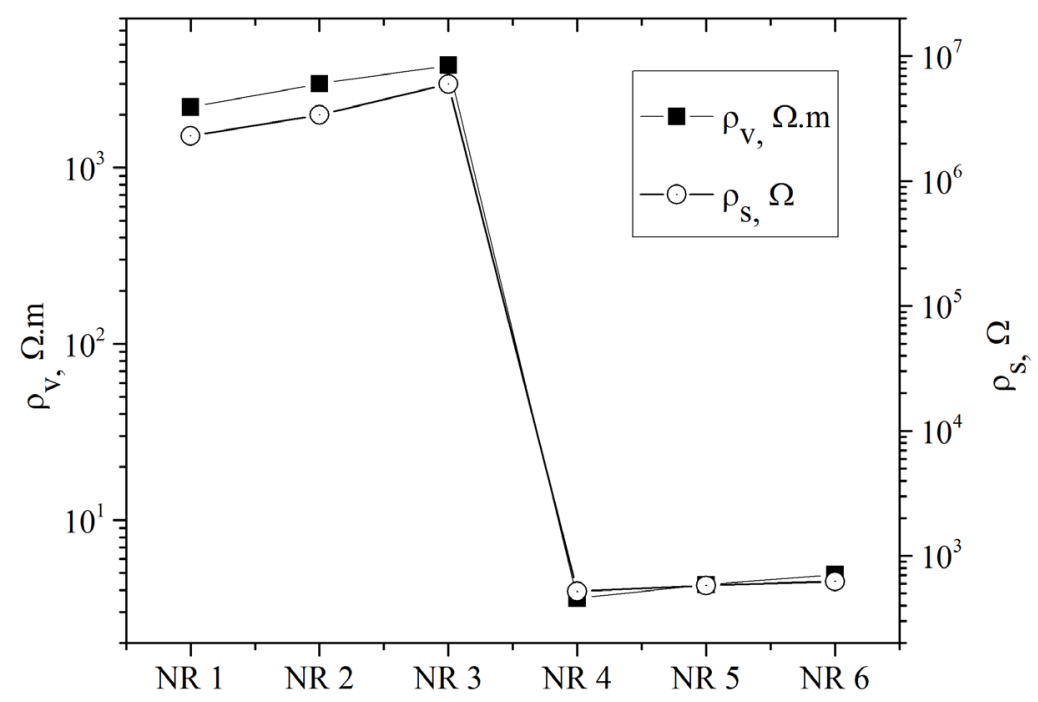

Figure 1. Volume resistivity and $\left(\rho_{v}\right)$ surface resistivity $\left(\rho_{s}\right)$ of the studied composites. 
$75 \mathrm{~m}^{2} / \mathrm{g}$, that of Printex XE-2B-1000 $\mathrm{m}^{2} / \mathrm{g}$ [40]. The smaller particles of Printex XE-2B, their higher specific surface area, respectively, favours the formation of conductive pathways, even at lower filler concentrations what is a prerequisite for higher conductivity.

Evidently in all cases, the volume resistivity and surface resistivity values for the composites comprising the investigated hybrid fillers increase with the increasing silica amount in them, i.e. their conductivity decreases. That is due to the silica phase penetration amongst the chain-like structures of carbon black [41]. Thus, the dielectric phase insulates the conductive one and the formation of conductive pathways is hindered, hence conductivity of the composite is lower. The results obtained are in full accordance with our working hypothesis.

\subsection{Dielectric Properties}

Figure 2 and Figure 3 present the frequency dependencies of the real part $\left(\varepsilon_{r}^{\prime}\right)$ and imaginary part $\left(\varepsilon^{\prime \prime}\right)$ of permittivity of the studied composites.

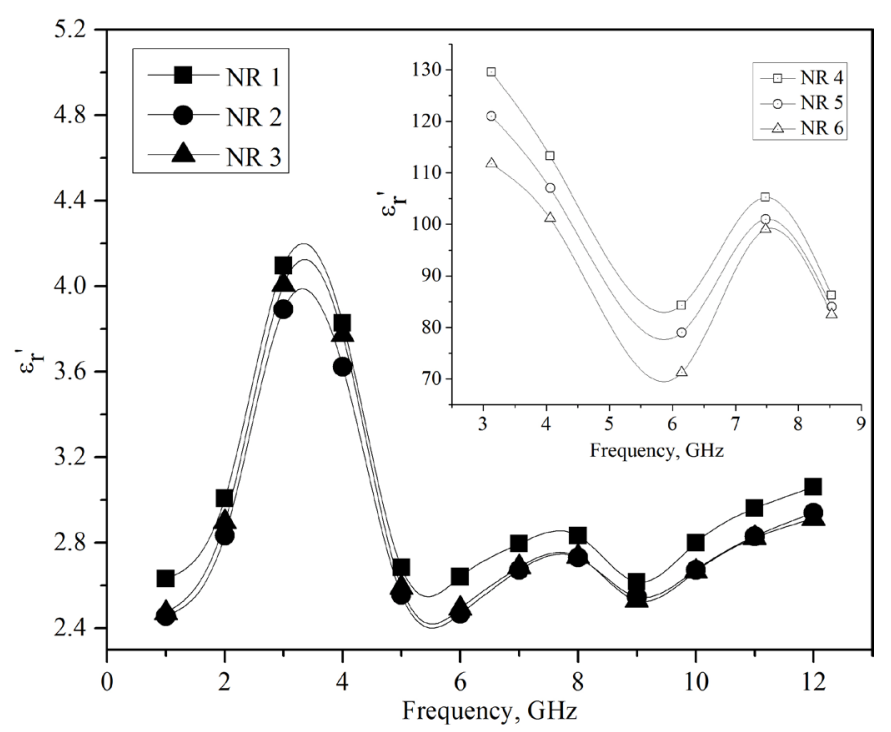

Figure 2. Frequency dependence of the real part of permittivity $\left(\varepsilon_{r}^{\prime}\right)$ of the studied composites.

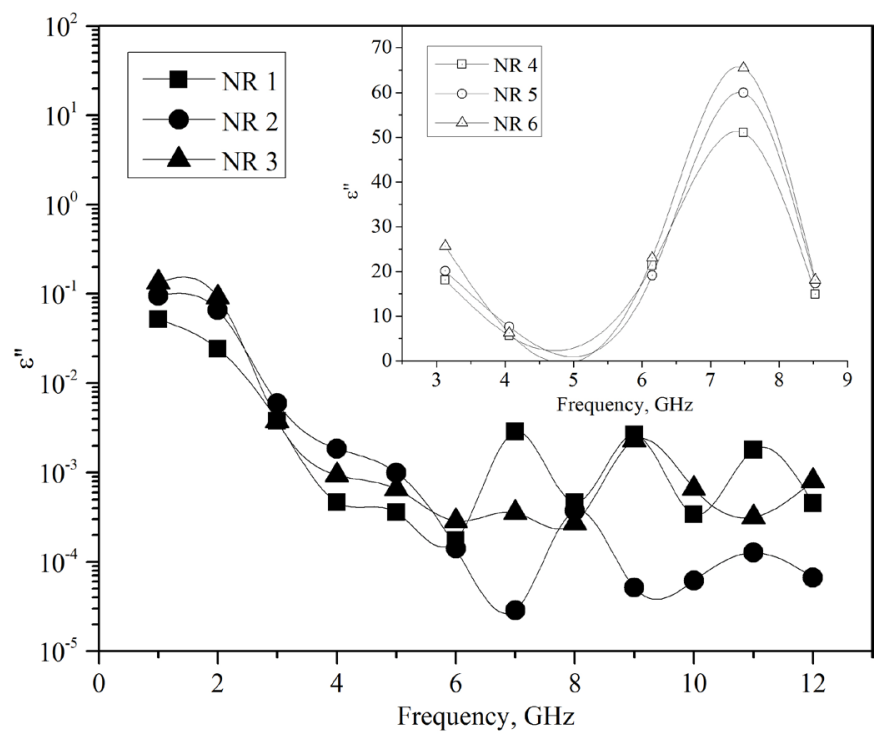

Figure 3. Frequency dependence of the imaginary part of permittivity $\left(\varepsilon^{\prime \prime}\right)$ of the studied composites. 
As Figure 2 shows, in the entire frequency range, $\varepsilon_{r}^{\prime}$ values for NR 1 comprising virgin carbon black are the highest of those for the composites comprising furnace carbon black N 330 and the hybrid fillers on its base. That is due to the interfacial polarization resulting from the inhomogeneity introduced by the filler particles and the conductive pathways they have built. The higher $\varepsilon_{r}^{\prime}$ values in the case reveal that, the molecular polarization is accomplished easily [42]. The $\varepsilon_{r}^{\prime}$ values of composites NR 2 and NR 3 comprising the hybrid fillers prepared by impregnation of furnace carbon black N 330 with silicasol are slightly lower than those of composite NR 1 filled with the substrate N 330 carbon black. The penetration of the silica phase amongst the chain structures of carbon black and their isolation hinders the formation of conductive pathways. That hampers the molecular polarization, therefore the real part of permittivity of the composites obtained is lower [41]. The higher dielectric silica phase amount in the hybrid fillers, the more pronounced its impact is. Similar effects have been observed for the composites comprising Printex XE-2B conductive carbon black and the hybrid fillers based on it (NR 4, NR 5 and NR 6). However, in the case the dielectric constant values are much higher ( $\varepsilon_{r}^{\prime}$ varies from 112 to 130 at $3 \mathrm{GHz}$ ) than those for the composites filled with furnace carbon black ( $\varepsilon_{r}^{\prime}$ varies from 3.8 to 4.2 at $3 \mathrm{GHz}$ ). That is due to the difference in the particle size of the two fillers and to the difference in their ability to form chain structures (conductive pathways). The smaller size of Printex XE-2B carbon black particles and their aptitude to form chain structures favour the formation of conductive pathways. Hence, the interfacial polarization resulting from inhomogeneity introduced by the filler particles becomes easier and consequently the real part of permittivity gets higher.

Figure 3 shows $\varepsilon^{\prime \prime}$ to be a parameter very sensitive to frequency. As seen, $\varepsilon^{\prime \prime}$ values for the composites filled with conductive carbon black Printex XE-2B are higher than those for composites with furnace carbon black N 330. The result may also be assigned to the differences in their structurality and main characteristics.

\subsection{Microwave Properties}

Figure 4 and Figure 5 present the frequency dependencies of the reflection loss and coefficient of attenuation of the composites studied.

As Figure 4 shows, the reflection loss values for the composites filled with furnace carbon black N 330 (NR 1), as well as for those comprising fillers on its base (NR 2 and NR 3), as determined by the amount of the second (dielectric) phase, do not differ significantly. Apparently, in the case, the low values (less than $-10 \mathrm{~dB}$ ) are observed in the $1 \mathrm{GHz}$ to $3 \mathrm{GHz}$ bandwidth. In the $3 \mathrm{GHz}$ to $12 \mathrm{GHz}$ range the reflective loss values are higher than $-10 \mathrm{~dB}$. That indicates matching between the impedance of free space and the impedance of the investigated material only in the $1 \mathrm{GHz}$ to $3 \mathrm{GHz}$ frequency range, i.e. the electromagnetic wave penetrates the sample. At higher frequencies the greater portion of the electromagnetic wave is reflected by the sample. As seen from

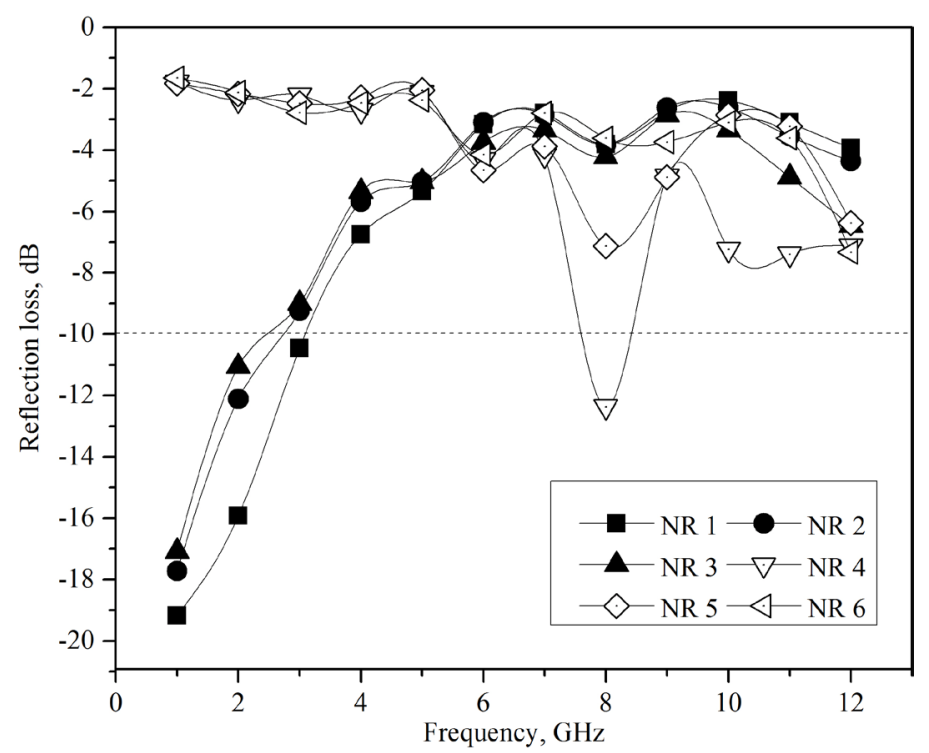

Figure 4. Reflection loss of the studied composites. 


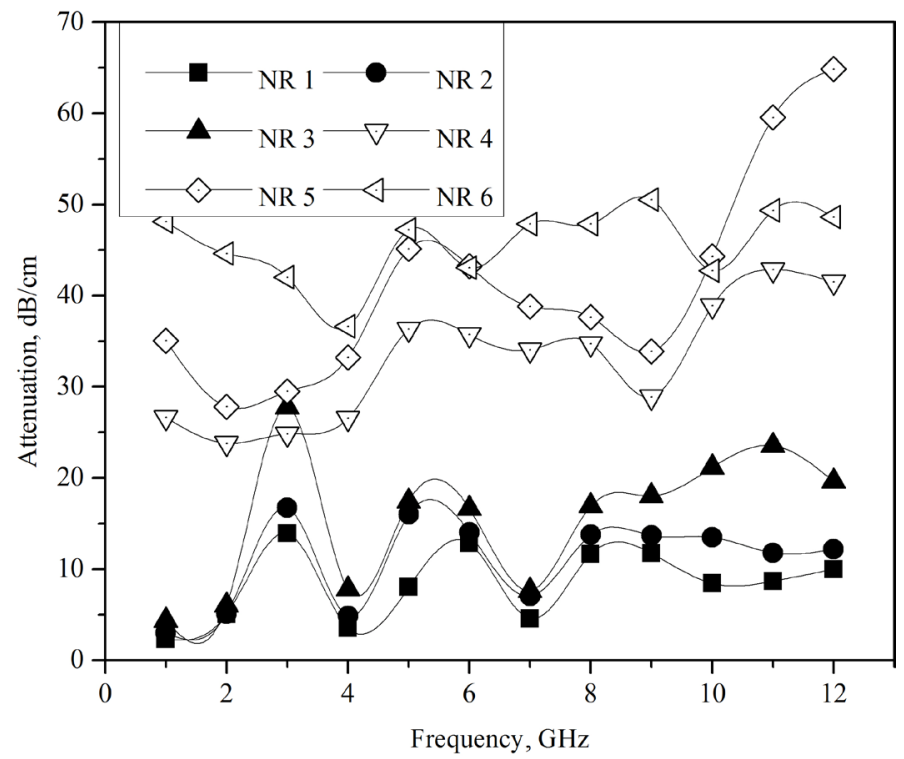

Figure 5. Attenuation coefficient of the studied composites.

Figure 5, the second phase has a better pronounced effect upon the attenuation coefficient. Evidently, the higher silica amounts improve the electromagnetic attenuation. Nonetheless, the attenuation coefficient values for the composites investigated are too low, while the ones for the reflection are too high. Hence, the composites filled with furnace carbon black N 330 and those with hybrid fillers on its base are unsuitable microwave absorbing materials. To produce good microwave absorbers one needs composites of low reflection and good attenuation properties. There are two methods for achieving low reflection. The first one involves making so that the electromagnetic waves are attenuated completely by the composite. The method is hard to accomplish, therefore researchers prefer the second one which consists of letting the electromagnetic wave penetrate the composite as much as possible and be attenuated by the absorbing material. Practically that can be realized by matching the impedance of free space with the material's impedance. The necessary condition is that the real part of magnetic permeability $\left(\mu^{\prime}\right)$ and the real part of the dielectric permittivity $\left(\varepsilon_{r}^{\prime}\right)$ should be equal, i.e. $\mu^{\prime} / \varepsilon_{r}^{\prime}=1$ [12], [43]. Keeping in mind that, carbon black does not possess magnetic properties, the condition cannot be fulfilled in the case studied because the dielectric constant of the composites comprising furnace carbon black N 330 and the hybrid fillers based on it is much higher than their magnetic permeability [44]. When matching between the impedance of free space and material's impedance is achieved, i.e. the electromagnetic wave having penetrated the material should be attenuated, the necessary condition is that, the imaginary part of permittivity ( $\left.\varepsilon^{\prime \prime}\right)$ and the imaginary part of permeability ( $\left.\mu^{\prime \prime}\right)$ should be higher [12], [43].

As Figure 4 shows, the reflection loss values for the composites comprising conductive carbon black Printex $\mathrm{XE}-2 \mathrm{~B}$ and the hybrid fillers on its base in all cases are higher than $-10 \mathrm{~dB}$. In the case that means the impedance of the free space mismatches the impedance of the material, i.e. the samples reflect the greater portions of incident electromagnetic waves. The fact is due to the higher conductivity of the fillers studied which is closer to the one metals have. However, as seen from Figure 5, the composites comprising conductive carbon black Printex XE-2B and the hybrid fillers on its base have electromagnetic attenuation values much higher than those for the composites filled with furnace carbon black N 330. The tendency of an increasing attenuation coefficient with the increasing silica amount in the hybrid fillers has also been observed in the case. That is due to the penetration of the silica phase amongst the chain structures of carbon black which isolation hinders the formation of conductive pathways.

The more pronounced ability of the composites comprising conductive carbon black Printex XE-2B and the hybrid fillers on its base to attenuate the electromagnetic waves could be explained examining thoroughly the reflection losses presented in Figure 4 and the electromagnetic interference shielding effectiveness presented in Figure 6. As seen from Figure 4, the reflection loss for the composite comprising hybrid filler based on Printex $\mathrm{XE}-2 \mathrm{~B}$ and $3 \%$ of silica (NR 5), for instance, at $1 \mathrm{GHz}$ is about $-1.8 \mathrm{~dB}$, i.e. the value of the reflection coeffi- 


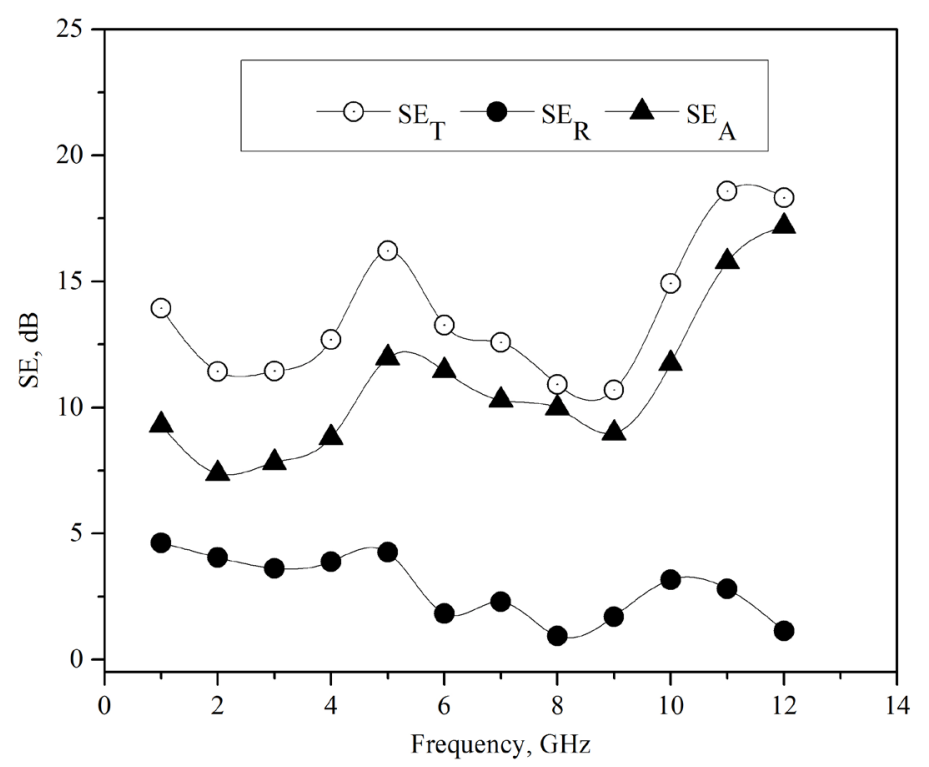

Figure 6. Frequency dependence of electromagnetic interference shielding effectiveness of the composite NR 5.

cient $|\Gamma|$ is about 0.81 . The amplitude of the reflected wave will be approximately $81 \%$ of the incident wave. That means the power of the reflected wave will be $66 \%$ of the power of the incident wave $\left(P_{I}\right)$. According to Equation (7) and Figure 6, the reflective shielding effectiveness in that case is about $4.6 \mathrm{~dB}$ at $1 \mathrm{GHz}$. According to the law of conservation of energy, the wave penetrating the sample will have power equal to $34 \%$ of that of the incident wave. In accordance with Figure 6, the total shielding effectiveness $\left(S E_{T}\right)$ at $1 \mathrm{GHz}$ is approximately $14 \mathrm{~dB}$. As it is clear from Equation (6), the transmitted power $\left(P_{T}\right)$ is approximately $4 \%$ of the incident power $\left(P_{I}\right)$. According to Equations (6), (8) and (10), the low $P_{T}$ value determines the high $S E_{A}$ value, the higher attenuation, as well as the dominating absorption character of the microwave shielding effectiveness. The more pronounced ability of the composites comprising conductive carbon black Printex XE-2B and the hybrid fillers on its base to attenuate the electromagnetic waves could be also explained by their higher values of the imaginary part of permittivity. Thus they meet the requirements for a good attenuation of electromagnetic waves. Though, there is a noteworthy drawback in the case- - the undesired greater dielectric heating resulting from the higher $\varepsilon^{\prime \prime}$ values [43].

Figure 7 presents the frequency dependence of electromagnetic interference shielding effectiveness of the composite, comprising the hybrid filler based on furnace carbon black N 330 and 3\% of silica. As seen, the total shielding effectiveness values of the composites filled with furnace carbon black are about three times lower than those of the composites comprising conductive carbon black. It could be said in the case that, reflection is the predominating component in the total shielding effectiveness.

The composites obtained, those comprising conductive carbon black Printex XE-2B and the hybrid fillers on its base, in particular, could find wide application in various areas of electronics. Their total shielding effectiveness values (varying between 14 and $19 \mathrm{~dB}$ ), guarantee electromagnetic shielding of $95 \%$ and make them valuable for manufacturing electromagnetic interference shielding materials [45]-[47]. Their high electric conductivity and relatively high ability to attenuate the electromagnetic waves, make them suitable for other applications as well—namely as antennas for mobile devices, automobiles, sensors and military-related applications. Of course, the applications could be much more provided that, the properties of the composites discussed above are improved. It is affordable by a more precise optimization of the amount ratio between the conductive and dielectric phases in the hybrid fillers, as well as by appropriating concentration of those fillers in the elastomer composites.

\section{Conclusion}

A comparison has been made of the electric, dielectric and microwave properties of natural rubber based com- 


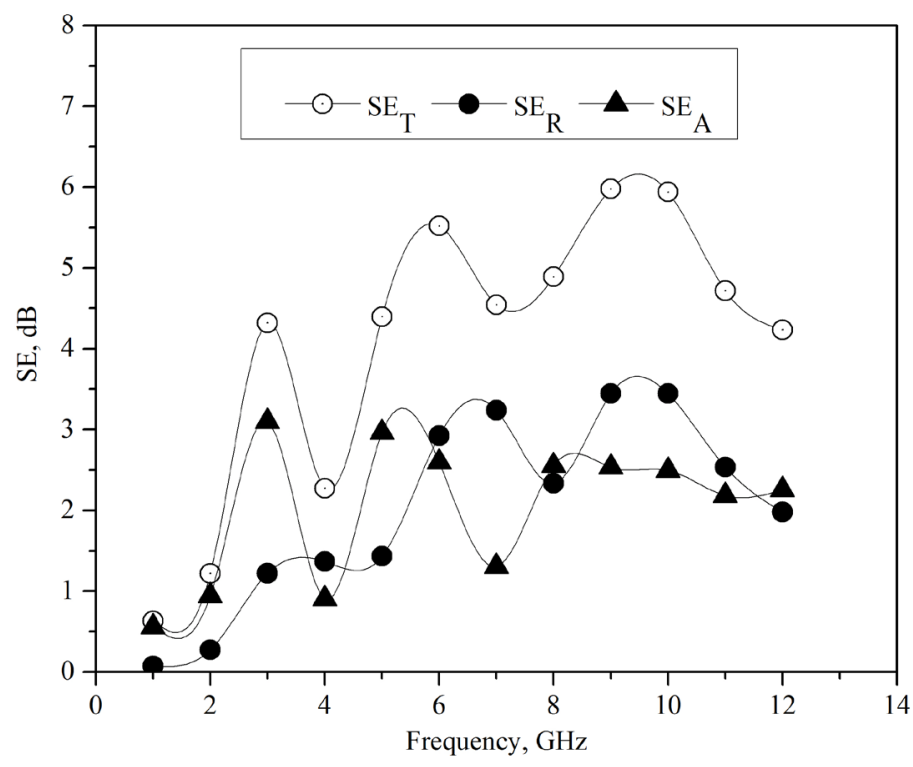

Figure 7. Frequency dependence of electromagnetic interference shielding effectiveness of the composite NR 2.

posites comprising dual phase fillers based on furnace carbon black or conductive carbon black and different amounts of silica. It has been established that, the specifics of the carbon phase have a marked strong effect upon the properties mentioned above. The interpenetration of the two filler phases and the grade of isolation of the conductive carbon phase by the dielectric one depend on the ratio between them. On the other hand, that leads to a change in all properties of the studied composites, what allows tailoring those characteristics. With an increasing amount of the dielectric phase in the hybrid fillers, the electric conductivity and dielectric constant of the composites get lower, while their ability to absorb electromagnetic waves enhances. The higher electroconductivity and the relatively high ability of the composites comprising conductive carbon black to attenuate the electromagnetic waves, make them suitable for several applications such as electromagnetic interference shielding materials, antennas for mobile devices, automobiles, sensors and military-related applications, as they meet the requirements set for the properties that such type of materials should possess.

\section{Acknowledgements}

The work is a part of a project, funded by King Abdulaziz University, Saudi Arabia under grant number MB/11/12/436. The authors acknowledge the technical and financial support.

\section{References}

[1] Ghasemi, A., Liu, X. and Morisako, A. (2007) Magnetic and Microwave Absorption Properties of BaFe $\mathrm{B}_{12-\mathrm{x}}$ $\left(\mathrm{Mn}_{0.5} \mathrm{Cu}_{0.5} \mathrm{Zr}\right)_{\mathrm{x} / 2} \mathrm{O}_{19}$ Synthesized by Sol-Gel Processing. Journal of Magnetism and Magnetic Materials, 316, e105e108. http://dx.doi.org/10.1016/j.jmmm.2007.02.043

[2] Yusoff, A.N., Abdullah, M.H., Ahmad, S.H., Jusoh, S.F., Mansor, A.A. and Hamid, S.A.A. (2002) Electromagnetic and Absorption Properties of Some Microwave Absorbers. Journal of Applied Physics, 92, 876-882. http://dx.doi.org/10.1063/1.1489092

[3] Chung, D.D.L. (2000) Materials for Electromagnetic Interference Shielding. Journal of Materials Engineering and Performance, 9, 350-354. http://dx.doi.org/10.1361/105994900770346042

[4] Chung, D.D.L. (2012) Carbon Materials for Structural Self-Sensing, Electromagnetic Shielding and Thermal Interfacing. Carbon, 50, 3342-3353. http://dx.doi.org/10.1016/j.carbon.2012.01.031

[5] Qin, F. and Brosseau, C. (2012) A Review and Analysis of Microwave Absorption in Polymer Composites Filled with Carbonaceous Particles. Journal of Applied Physics, 111, Article ID: 061301. http://dx.doi.org/10.1063/1.3688435

[6] Sunny, V., Kurian, P., Mohanan, P., Joy, P.A. and Anantharaman, M.R. (2010) A Flexible Microwave Absorber Based on Nickel Ferrite Nanocomposite. Journal of Alloys and Compounds, 489, 297-303. 
http://dx.doi.org/10.1016/j.jallcom.2009.09.077

[7] Jamal, E.M.A., Mohanan, P., Joy, P.A., Kurian, P. and Anantharaman, M.R. (2009) Effect of Nickel Nanofillers on the Dielectric and Magnetic Properties of Composites Based on Rubber in the X-Band. Applied Physics A, 97, 157-165. http://dx.doi.org/10.1007/s00339-009-5284-1

[8] Prema, K.H., Kurian, P., Anantharaman, M.R., Suma, M.N. and Joseph, M. (2008) Permittivity Characteristics in the X- and S-Band Frequencies of Microwave Absorbers Based on Rubber Ferrite Composites. Journal of Elastomers and Plastics, 40, 331-346. http://dx.doi.org/10.1177/0095244307088043

[9] Sunny, V., Kumar, D.S., Mohanan, P. and Anantharaman, M.R. (2010) Nickel/Carbon Hybrid Nanostructures as Microwave Absorbers. Materials Letters, 64, 1130-1132. http://dx.doi.org/10.1016/j.matlet.2010.02.010

[10] Miyata, Y. and Matsumoto, M. (1997) Two-Layer Wave Absorber Composed of Soft-Magnetic and Ferroelectric Substances. IEEE Transactions on Magnetics, 33, 3427-3429. http://dx.doi.org/10.1109/20.617966

[11] Feng, Y., Qiu, T., Li, X. and Shen, C. (2007) Microwave Absorption Properties of the Carbonyl Iron/EPDM Radar Absorbing Materials. Journal of Wuhan University of Technology-Mater. Sci. Ed., 22, 266-270.

[12] Duggal, S. and Aul, G.D. (2014) Review on Effect of Electric Permittivity and Magnetic Permeability Over Microwave Absorbing Materials at Low Frequencies. International Journal of Engineering and Advanced Technology (IJEAT), 3, 12-19.

[13] Barba, A.A., Lamberti, G., d'Amore, M. and Acierno, D. (2006) Carbon Black/Silicone Rubber Blends as Absorbing Materials to Reduce Electro Magnetic Interferences (EMI). Polymer Bulletin, 57, 587-593. http://dx.doi.org/10.1007/s00289-006-0598-z

[14] Joshi, A. and Datar, S. (2015) Carbon Nanostructure Composite for Electromagnetic Interference Shielding. Pramana, 84, 1099-1116. http://dx.doi.org/10.1007/s12043-015-1005-9

[15] Krishnan, Y., Chandran, S., Usman, N., Smitha, T.R., Parameswaran, P.S. and Prema, K.H. (2015) Processability, Mechanical and Magnetic Studies on Natural Rubber-Ferrite Composites. International Journal of Chemical Studies, 3, $15-22$.

[16] Ismail, H., Sam, S.T., Mohd Noor, A.F. and Bakar, A.A. (2007) Properties of Ferrite-Filled Natural Rubber Composites. Polymer-Plastics Technology and Engineering, 46, 641-650. http://dx.doi.org/10.1080/03602550701305054

[17] Kong, I., Hj Ahmad, S., Hj Abdullah, M., Hui, D., NazlimYusoff, A. and Puryanti, D. (2010) Magnetic and Microwave Absorbing Properties of Magnetite-Thermoplastic Natural Rubber Nanocomposites. Journal of Magnetism and Magnetic Materials, 322, 3401-3409. http://dx.doi.org/10.1016/j.jmmm.2010.06.036

[18] Urogiova, E., Hudec, I. and Bellusova, D. (2006) Magnetic and Mechanical Properties of Strontium Ferrite-Rubber Composites. Kautschuk Gummi Kunststoffe, 59, 224-228.

[19] Dishovsky, N. (2009) Rubber Based Composites with Active Behaviour to Microwaves (Review). Journal of the University of Chemical Technology and Metallurgy, 44, 115-122.

[20] Yuan, Y., Zhang, S.R., Zhou, X.H. and Li, E.Z. (2013) $\mathrm{MgTiO}_{3}$ Filled PTFE Composites for Microwave Substrate Applications. Materials Chemistry and Physics, 141, 175-179. http://dx.doi.org/10.1016/j.matchemphys.2013.04.043

[21] Fan, B.-H., Zha, J.-W., Wang, D., Zhao, J. and Dang, Z.-M. (2012) Size-Dependent Low-Frequency Dielectric Properties in the $\mathrm{BaTiO}_{3} /$ Poly (Vinylidene Fluoride) Nanocomposite Films. Applied Physics Letters, 100, Article ID: 012903. http://dx.doi.org/10.1063/1.3673555

[22] Jin, S., Wang, L., Wang, Z., Huang, B., Zhang, Q. and Fu, Z. (2015) Dielectric Properties of Modified SrTiO $3 / \mathrm{PTFE}$ Composites for Microwave RF Antenna Applications. Journal of Materials Science: Materials in Electronics, 26, 7431-7437. http://dx.doi.org/10.1007/s10854-015-3374-8

[23] Ullah, U., Ali, W.F.F.W., Ain, M.F., Mahyuddin, N.M. and Ahmad, Z.A. (2015) Design of a Novel Dielectric Resonator Antenna Using $\mathrm{MgTiO}_{3}-\mathrm{CoTiO}_{3}$ for Wideband Applications. Materials \& Design, 85, 396-403. http://dx.doi.org/10.1016/j.matdes.2015.07.026

[24] Wang, M.J., Kutsovsky, Y., Zhang, P., Mehos, G., Murphy, L.J. and Mahmud, K. (2002) Using Carbon-Silica Dual Phase Filler Improve Global Compromise between Rolling Resistance, Wear Resistance and Wet Skid Resistance for Tires. Kautschuk Gummi Kunststoffe, 55, 33-40.

[25] Rattanasom, N., Saowapark, T. and Deeprasertkul, C. (2007) Reinforcement of Natural Rubber with Silica/Carbon Black Hybrid Filler. Polymer Testing, 26, 369-377. http://dx.doi.org/10.1016/j.polymertesting.2006.12.003

[26] Chen, L.F., Ong, C.K., Neo, C.P., Varadan, V.V. and Varadan, V.K. (2004) Microwave Electronics: Measurement and Materials Characterization. John Wiley \& Sons Ltd., Chichester. http://dx.doi.org/10.1002/0470020466

[27] Sheen, J. (2009) Measurements of Microwave Dielectric Properties by an Amended Cavity Perturbation Technique. Measurement, 42, 57-61. http://dx.doi.org/10.1016/j.measurement.2008.03.017

[28] Verma, A. and Dube, D.C. (2005) Measurement of Dielectric Parameters of Small Samples at X-Band Frequencies by 
Cavity Perturbation Technique. IEEE Transactions on Instrumentation and Measurement, 54, 2120-2123. http://dx.doi.org/10.1109/TIM.2005.854249

[29] Jana, P.B., Mallick, K. and De, S.K. (1992) Effects of Sample Thickness and Fiber Aspect Ratio on EMI Shielding Effectiveness of Carbon Fiber Filled Polychloroprene Composites in the X-Band Frequency Range. IEEE Transactions on Electromagnetic Compatibility, 34, 478-481. http://dx.doi.org/10.1109/15.179281

[30] Paul, C.R. (2006) Introduction to Electromagnetic Compatibility. 2nd Edition, John Wiley \& Sons Inc., Hoboken.

[31] Ott, H.W. (2009) Electromagnetic Compatibility Engineering. 1st Edition, John Wiley \& Sons Inc., Hoboken. http://dx.doi.org/10.1002/9780470508510

[32] Hernandez, B. (2013) Effect of Graphitic Carbon Nanomodifiers on the Electromagnetic Shielding Effectiveness of Linear Low Density Polyethylene Nanocomposites. Ph. D. Thesis, the Graduate School of Clemson University, Clemson.

[33] Srikanth, V.V.S.S. and Raju, K.C.J. (2015) Graphene/Polymer Nanocomposites as Microwave Absorbers. In: Sadasivuni, K.K., Ed., Graphene-Based Polymer Nanocomposites in Electronics, Springer International Publishing, Burlin, 307-343. http://dx.doi.org/10.1007/978-3-319-13875-6 12

[34] Sung-Hoon, P., Theilmann, P.T., Asbeck, P.M. and Bandaru, P.R. (2010) Enhanced Electromagnetic Interference Shielding through the Use of Functionalized Carbon-Nanotube-Reactive Polymer Composites. IEEE Transactions on Nanotechnology, 9, 464-469. http://dx.doi.org/10.1109/TNANO.2009.2032656

[35] Hong, Y.K., Lee, C.Y., Jeong, C.K., Lee, D.E., Kim, K. and Joo, J. (2003) Method and Apparatus to Measure Electromagnetic Interference Shielding Efficiency and Its Shielding Characteristics in Broadband Frequency Ranges. Review of Scientific Instruments, 74, 1098-1102. http://dx.doi.org/10.1063/1.1532540

[36] Rahaman, M., Chaki, T.K. and Khastgir, D. (2011) Development of High Performance EMI Shielding Material from EVA, NBR, and Their Blends: Effect of Carbon Black Structure. Journal of Materials Science, 46, 3989-3999. http://dx.doi.org/10.1007/s10853-011-5326-x

[37] Sohi, N.J.S., Rahaman, M. and Khastgir, D. (2011) Dielectric Property and Electromagnetic Interference Shielding Effectiveness of Ethylene Vinyl Acetate-Based Conductive Composites: Effect of Different Type of Carbon Fillers. Polymer Composites, 32, 1148-1154. http://dx.doi.org/10.1002/pc.21133

[38] Sohi, N.J.S., Bhadra, S. and Khastgir, D. (2011) The Effect of Different Carbon Fillers on the Electrical Conductivity of Ethylene Vinyl Acetate Copolymer-Based Composites and the Applicability of Different Conductivity Models. Carbon, 49, 1349-1361.http://dx.doi.org/10.1016/j.carbon.2010.12.001

[39] Selvin Thomas, P., Abdullateef, A.A., Al-Harthi, M.A., Atieh, M.A., De, S.K., Rahaman, M., Chaki, T.K., Khastgir, D. and Bandyopadhyay, S. (2011) Electrical Properties of Natural Rubber Nanocomposites: Effect of 1-Octadecanol Functionalization of Carbon Nanotubes. Journal of Materials Science, 47, 3344-3349. http://dx.doi.org/10.1007/s10853-011-6174-4

[40] Al-Hartomy, O.A., Al-Solamy, F., Al-Ghamdi, A., Dishovsky, N., Ivanov, M., Mihaylov, M. and El-Tantawy, F. (2011) Influence of Carbon Black Structure and Specific Surface Area on the Mechanical and Dielectric Properties of Filled Rubber Composites. International Journal of Polymer Science, 2011, Article ID: 521985. http://dx.doi.org/10.1155/2011/521985

[41] Al-Ghamdi, A.A., Al-Hartomy, O.A., Al-Solamy, F.R., Dishovsky, N., Malinova, P. and Lakov, L. (2015) Characterization of Hybrid Fillers Based on Carbon Black of Different Types Obtained by Impregnation. Proceedings of the Institution of Mechanical Engineers, Part L: Journal of Materials: Design and Applications, In Press.

[42] Puryanti, D., Ahmad, S.H. and Abdullah, M.H. (2006) Effect of Nickel-Cobalt-Zinc Ferrite Filler on Electrical and Mechanical Properties of Thermoplastic Natural Rubber Composites. Polymer-Plastics Technology and Engineering, 45, 561-567. http://dx.doi.org/10.1080/03602550600554166

[43] Zhang, B., Yong, F., Jie, X., Yang, Y. and Lu, H. (2006) Microwave-Absorbing Properties of De-Aggregated FlakeShaped Carbonyl-Iron Particle Composites at 2 - 18 GHz. IEEE Transactions on Magnetics, 42, 1778-1781. http://dx.doi.org/10.1109/TMAG.2006.874188

[44] Xie, S., Yang, Y., Hou, G., Wang, J. and Ji, Z. (2016) Development of Layer Structured Wave Absorbing Mineral Wool Boards for Indoor Electromagnetic Radiation Protection. Journal of Building Engineering, 5, 79-85. http://dx.doi.org/10.1016/j.jobe.2015.11.008

[45] Faisal, M. and Khasim, S. (2014) Ku-Band EMI Shielding Effectiveness and Dielectric Properties of Polyaniline-Y2O3 Composites. Polymer Science Series A, 56, 366-372. http://dx.doi.org/10.1134/S0965545X14030055

[46] Wu, Z.P., Li, M.M., Hu, Y.Y., Li, Y.S., Wang, Z.X., Yin, Y.H., Chen, Y.S. and Zhou, X. (2011) Electromagnetic Interference Shielding of Carbon Nanotube Macrofilms. Scripta Materialia, 64, 809-812. http://dx.doi.org/10.1016/j.scriptamat.2011.01.002

[47] Dhawan, S.K., Singh, N. and Venkatachalam, S. (2002) Shielding Behaviour of Conducting Polymer-Coated Fabrics in X-Band, W-Band and Radio Frequency Range. Synthetic Metals, 129, 261-267. http://dx.doi.org/10.1016/S0379-6779(02)00079-6 